\title{
Knockdown of IncRNA NEAT1 suppresses proliferation and migration, and induces apoptosis of cervical cancer cells by regulating the miR-377/FGFR1 axis
}

\author{
FENG GENG $^{1}$, WEN-CONG JIA ${ }^{2}$, TAO LI ${ }^{1}$, NA LI $^{1}$ and WEI WEI ${ }^{1}$ \\ ${ }^{1}$ Department of Obstetrics and Gynecology, Shandong Provincial Hospital Affiliated to \\ Shandong First Medical University, Jinan, Shandong 250021; ${ }^{2}$ Department of Obstetrics and Gynecology, \\ Binzhou Second People's Hospital, Binzhou, Shandong 256800, P.R. China
}

Received August 11, 2020; Accepted March 8, 2021

DOI: $10.3892 / \mathrm{mmr} .2021 .12526$

\begin{abstract}
To investigate the role of NEAT1 and the microRNA (miR)-377/fibroblast growth factor receptor 1 (FGFR1) axis in cervical cancer (CC), the expression levels of NEAT1, FGFR1 and miR-377 were detected in CC tissues and cell lines. NEAT1 or FGFR1 was knocked down by transfection with short hairpin RNA (sh)-NEAT1 or sh-FGFR1, and miR-377 was overexpressed by transfection with miR-377 mimics in $\mathrm{HeLa}$ and C33A cells. Cell viability and migration were measured using MTT and Transwell assays, respectively. Cell apoptosis was determined by flow cytometry. A dual luciferase reporter assay was performed to confirm the presence of binding sites between miR-377 and FGFR1. The results revealed that the expression levels of NEAT1 and FGFR1 were significantly elevated, whereas miR-377 expression was markedly decreased in CC tissues and cell lines. In HeLa and C33A cells, after NEAT1 knockdown, miR-377 expression was increased, cell viability and migration were inhibited, and apoptosis was induced. Similarly, silencing FGFR1 inhibited cell viability and migration, and induced apoptosis of $\mathrm{HeLa}$ and C33A cells. A dual luciferase reporter gene assay verified a targeting relationship between NEAT1 and miR-377. Inhibition of miR-377 or overexpression of FGFR1 reversed the effects of NEAT1 knockdown on cell function in HeLa and C33A cells. Moreover, a dual luciferase reporter assay confirmed that FGFR1 was a direct target of miR-377. In conclusion, suppression of NEAT1 inhibited cell viability and migration, and promoted apoptosis of CC cells, and these effects were achieved through regulation of the miR-377/FGFR1 axis.
\end{abstract}

Correspondence to: Dr Wei Wei, Department of Obstetrics and Gynecology, Shandong Provincial Hospital Affiliated to Shandong First Medical University, 324 Jingwu Road, Jinan, Shandong 250021, P.R. China

E-mail: runningweiwei@126.com

Key words: NEAT1, cervical cancer, microRNA-377, fibroblast growth factor receptor 1

\section{Introduction}

According to previous reports, cervical cancer (CC) is the second most common gynecological malignant tumor, which accounts for $\sim 527,624$ new cases and 265,672 deaths every year worldwide, and is particularly prevalent in low-income and middle-income countries (1-3). Since most patients with $\mathrm{CC}$ are at an advanced stage when diagnosed, the prognosis and 5-year survival rate of patients with CC remain poor (4). In recent decades, oncogenes and anticancer genes have been widely noted in cancer development, including in CC $(5,6)$; however, despite numerous studies, the molecular mechanism underlying $\mathrm{CC}$ remains unclear.

Long non-coding RNAs (lncRNAs) are a type of non-coding RNA that are comprised of $>200$ nucleotides, and have been reported to serve important roles in various diseases, including CC (7). Yuan et al (8) revealed that 190 lncRNAs and 2,326 protein-coding genes were differentially expressed in samples obtained from patients with CC. Another study reported that 5,844 lncRNAs and 4,436 genes were abnormally expressed in CC samples compared with in normal cervical tissues (9). Among lncRNAs, NEAT1 is a newly identified lncRNA (10). Previous studies have demonstrated that NEAT1 could promote the development of several types of cancer, such as lung cancer and breast cancer $(11,12)$. In addition, Yuan et al $(13)$ revealed that NEAT1 was overexpressed in CC and suggested that it may promote $\mathrm{CC}$ development by regulating the microRNA (miRNA/miR)-133a/SOX4 axis (13). In another recent study, NEAT1 was demonstrated to promote the growth of CC cells by sponging miR-9-5p (14). However, the molecular mechanisms underlying the role of NEAT1 in CC are not yet fully understood.

miRNAs are endogenous small RNAs that comprise 20-24 nucleotides (15). In recent years, the role of miRNAs in CC development has been gradually revealed. Park et al (16) demonstrated that miR-9, miR-21 and miR-155 were significantly elevated in CC tissues, and may have potential as biomarkers of CC. In a recent study, Babion et al (17) detected low levels of miR-9-5p in adenocarcinoma, and reported that miR-9-5p acted as either a cancer promotor or suppressor in CC cells depending on histotype and high-risk human papilloma 
virus type (17). miR-377 is generally considered a cancer suppressor that inhibits the development of various types of cancer, such as lung cancer and esophageal cancer $(18,19)$. In a recent study, the miR-377/fibroblast growth factor receptor 1 (FGFR1) axis was revealed to be involved in hepatocellular carcinoma (20). FGFR1 is a member of the FGFR family that acts as an oncogene and is expressed in numerous types of cancer (21). However, to the best of our knowledge, the roles of miR-377 and FGFR1 in CC are still unknown.

The present study aimed to investigate the role of NEAT1 and the miR-377/FGFR1 axis in CC cells. The relationship between NEAT1 and CC proliferation and migration was investigated at the clinical and cellular levels. Further cell experiments revealed that NEAT1 could affect the development of CC by regulating the miR-377/FGFR1 axis. These results may provide novel research targets to identify the molecular mechanisms underlying CC.

\section{Materials and methods}

Tissues. A total of 10 paired $\mathrm{CC}$ and adjacent non-CC tissue samples were obtained from patients with CC (age, 48-65 years) who underwent radical resection at Department of Obstetrics and Gynecology, Shandong Provincial Hospital (Jinan, China) between March 2018 and June 2019. The patient did not receive chemotherapy or radiation therapy. All samples were confirmed histologically, frozen immediately after being surgically resected from the patients and stored at $-80^{\circ} \mathrm{C}$ before use. Written informed consent was obtained from all patients for the biological studies, and the present study was approved by the Ethics Committee of Shandong Provincial Hospital.

Cell culture and translation. The human CC cell lines CaSki, C33A and HeLa were purchased from American Type Culture Collection. The HCE1 CC cell line was obtained from Xiangya Medical College Cancer Institute. The HCE1 cells used in the present study are also known as Hunan cervical epithelial cell line no. 1; this cell line was established by Chinese researchers in 2000 (22). The normal cervical epithelial cell line ende1617 was purchased from Shanghai Yaji Biological Technology Co., Ltd. (cat. no. YS3573C). Cells were cultured in RPMI-1640 supplemented with $10 \% \mathrm{FBS}$ and $100 \mu \mathrm{g} / \mathrm{ml}$ penicillin-streptomycin (all Gibco; Thermo Fisher Scientific, Inc.) at $37^{\circ} \mathrm{C}$ with 5\% $\mathrm{CO}_{2}$. For cell transfection, short hairpin RNA (sh)-NEAT1, miR-377 mimics, miR-377 inhibitor and sh-FGFR1, as well as negative controls (NCs: mimic NC, inhibitor NC and sh-NC), were designed and synthesized by Shanghai GeneChem Co., Ltd. pcDNA3.1 vector and FGFR1pcDNA3.1 overexpression vector were designed and synthesized by Invitrogen; Thermo Fisher Scientific, Inc. (sh-NEAT1, 5'-CAACACCTTAGACACAAACACGAGCTCGTGTTTGT GTCTAAGGTGTTG-3'; sh-FGFR1, 5'-CGAGGCATTATTT GACCGGAT-3'; miR-377 mimics, 5'-AUCACACAAAGGCA ACUUUUGU-3'; miR-377 inhibitor, 5'-ACAAAAGUUGCC UUUGUGUGAU-3'; mimic NC, 5'-UUUUACUACACAAAA GUACUG-3'; inhibitor NC, 5'-CAGUACUUUUGUGUAG UACAAA-3'; sh-NC, 5'-GATCCCCTTCTCCGAACGTGTC ACGTTTCAAGAGAACGTGACACGTTCGGAGAA-3'). Cells were transfected with the aforementioned sh-NEAT1 $(50 \mathrm{pM})$, miR-377 mimics (50 nM), miR-377 inhibitor (100 nM),
sh-FGFR1 (50 pmol), FGFR1 (50 nM) overexpression vectors and NCs $\left(100 \mathrm{nM}\right.$ ) using Lipofectamine ${ }^{\circledR} 2000$ (Invitrogen; Thermo Fisher Scientific, Inc.) according to the manufacturer's instructions. Briefly, $2 \times 10^{5}$ cells were cultured in 6-well plates. After reaching 60-68\% confluence, cells were transfected with miRNA mimics or inhibitor, shRNAs or vectors at $37^{\circ} \mathrm{C}$ in $5 \% \mathrm{CO}_{2}$. After $48 \mathrm{~h}$, the subsequent experiments were performed.

MTT assay. For MTT assays, HeLa and C33A cells were analyzed 24,48 and $72 \mathrm{~h}$ post-transfection. The cells were seeded in 96-well plates at a density of $3 \times 10^{3}$ cells/well and were cultured for $48 \mathrm{~h}$ at $37^{\circ} \mathrm{C}$ with $5 \% \mathrm{CO}_{2}$, followed by the addition of $10 \mu \mathrm{l}$ MTT solution $(5 \mathrm{mg} / \mathrm{ml})$. Cells were then cultured for a further $4 \mathrm{~h}$. After removal of the MTT and addition of $100 \mu \mathrm{l}$ DMSO, the optical density was evaluated at $490 \mathrm{~nm}$.

Transwell assay. To measure HeLa and C33A cells migration, a Transwell assay was conducted. Briefly, $200 \mu \mathrm{l}$ $5 \times 10^{4}$ cells $/ \mathrm{ml}$ were plated in the upper chamber of the entire plate without a coating membrane (24-well insert; pore size, $8 \mu \mathrm{m}$; BD Biosciences) in serum-free medium for $24 \mathrm{~h}$ at $37^{\circ} \mathrm{C}$, and RPMI-1640 containing $20 \%$ FBS was added to the lower chamber. Subsequently, the cells were stained with $0.1 \%$ crystal violet, counted and images were captured using a light microscope (Zeiss $\mathrm{GmbH}$ ).

Cell apoptosis. HeLa and C33A cells were digested with trypsin, collected and stained using an Annexin V/PI double staining kit (BD Biosciences) strictly according to the manufacturer's instructions. Cell apoptosis was measured via flow cytometry (AccuriC6; BD Biosciences). FlowJo version 7.6 (FlowJo LLC) was used to calculate the apoptotic rate.

Dual luciferase reporter assay. Dual luciferase reporter assays were performed to confirm a binding relationship between NEAT1 3'-UTR and miR-377, and between FGFR1 3'-untranslated region (UTR) and miR-377. The binding mode was predicted using TargetScan 7.2 (http://www.targetscan.org; Whitehead Institute for Biomedical Research). According to the manufacturer's protocol, the QuikChange II Site-Directed Mutagenesis kit (Agilent Technologies, Inc.) was used to mutate the 3'-UTRs. Briefly, wild-type (wt) NEAT1 or FGFR1 3'-UTR or mutant (mut) NEAT1 or FGFR1 3'-UTR was subcloned into a pGL4.10 luciferase reporter vector (Promega Corporation), followed by co-transfection with the $50 \mathrm{ng}$ wt or mut vectors and miR-377 mimics, miR-377 inhibitors or relevant NCs (at a final concentration of $20 \mathrm{nM}$ ) into HeLa and C33A cells using Lipofectamine 2000 in a 20- $\mu \mathrm{l}$ transfection system. HeLa and C33A cells $\left(2 \times 10^{5}\right)$ were cultured in 6-well plates and transfected when they reached $60-68 \%$ confluence. Subsequently, $48 \mathrm{~h}$ post-transfection, luciferase assays were performed using the Bright-Glo ${ }^{\mathrm{TM}}$ Luciferase Assay system (Promega Corporation), and the luciferase activity was normalized to Renilla luciferase activity values.

$R N A$ extraction and reverse transcription-quantitative PCR $(R T-q P C R)$ assay. The expression levels of NEAT1, FGFR1 and miR-377 were measured using RT-qPCR. Briefly, in cervical cancer tissues, adjacent tissues, HeLa and C33A cells, RNA or 
Table I. Clinicopathological characteristics of patients.

\begin{tabular}{|c|c|c|c|c|c|}
\hline Case no. & Age, years & Tumor diameter, $\mathrm{cm}$ & FIGO stage & Lymph node metastasis & HPV status \\
\hline 1 & 60 & $>4$ & III A & Yes & Negative \\
\hline 2 & 48 & $<4$ & II A & No & Positive \\
\hline 3 & 59 & $>4$ & III A & Yes & Positive \\
\hline 4 & 65 & $>4$ & III B & Yes & Negative \\
\hline 5 & 58 & $<4$ & II B & No & Negative \\
\hline 6 & 53 & $>4$ & IV A & Yes & Positive \\
\hline 7 & 58 & $>4$ & IV A & Yes & Positive \\
\hline 8 & 64 & $>4$ & III B & Yes & Positive \\
\hline 9 & 55 & $<4$ & I B2 & No & Positive \\
\hline 10 & 62 & $>4$ & III A & Yes & Positive \\
\hline
\end{tabular}

HPV, human papilloma virus.

miRNA extraction was performed using TRIzol ${ }^{\circledR}$ reagent (Invitrogen; Thermo Fisher Scientific, Inc.) or a mirVana miRNA isolation kit (Ambion; Thermo Fisher Scientific, Inc.). A High Capacity cDNA Reverse Transcription kit (Applied Biosystems; Thermo Fisher Scientific, Inc.) and a Taqman MicroRNA Reverse Transcription kit (Applied Biosystems; Thermo Fisher Scientific, Inc.) were used to convert RNA to cDNA for mRNA and miRNA detection, respectively. RNA extraction and RT were conducted according to the manufacturers' protocols. qPCR was conducted in an Applied Biosystems 7500 Real-Time PCR system (Applied Biosystems; Thermo Fisher Scientific, Inc.), according to the manufacturer's instructions, using SYBR ${ }^{\circledR}$ Premix Ex Taq ${ }^{\mathrm{TM}}$ (Takara Bio, Inc.) as a DNA-specific fluorescent dye. The reaction protocol included preheating at $95^{\circ} \mathrm{C}$ for $20 \mathrm{sec}$, and then 40 cycles of double-strand denaturation at $95^{\circ} \mathrm{C}$ for $5 \mathrm{sec}$ and rapid cooling to $60^{\circ} \mathrm{C}$ for $30 \mathrm{sec}$, after which the primers annealed and bound to the target sequence, and extension was performed at $65^{\circ} \mathrm{C}$ for $10 \mathrm{sec}$. The primer sequences used were as follows: NEAT1 forward, 5'-CGCGGATCCTGGATTTAGTAAGATTTG GGC-3', and reverse, 5'-CCGGAATTCACATGCAATTCA GGTCAGTG-3'; FGFR1 forward, 5'-GCCCATTCGATCTG GTGATT-3', and reverse, 5'-GGCGGTAGAACTCAAAGAA GAG-3'; miR-377 forward, 5'-TGGTTGTAGCAGCTTGTGTC TGG-3', and reverse, 5'-CCTGGTTTGTGCAAAGATACT GGG-3'; U6 forward, 5'-ATTGGAACGATACAGAGAAG ATT-3', and reverse 5'-GGAACGCTTCACGAATTTG-3'; GAPDH forward, 5'-CCACAGTCCATGCCATCAC-3', and reverse 5'-GCTTCACCACCTTCTTGATG-3'. The relative expression levels were calculated using the $2^{-\Delta \Delta C q}$ method (23). GAPDH and U6 were used as internal controls for mRNA and miRNA, respectively.

Western blotting. The protein expression levels of FGFR1 were determined via western blotting. Briefly, proteins were extracted from HeLa and C33A cells using M-PER ${ }^{\mathrm{TM}}$ Mammalian Protein Extraction Reagent (Invitrogen; Thermo Fisher Scientific, Inc.), and the total protein was quantified using the Pierce ${ }^{\mathrm{TM}}$ BCA protein quantification kit (Invitrogen; Thermo Fisher Scientific, Inc.). Proteins $(50 \mu \mathrm{g})$ were separated by SDS-PAGE on $10 \%$ gels, transferred to PVDF membranes and blocked with 5\% non-fat milk at room temperature for $1 \mathrm{~h}$. The membranes were then incubated with a primary anti-FGFR1 antibody (1:400; cat. no. ab10646; Abcam) at $4^{\circ} \mathrm{C}$ overnight, followed by incubation with a Goat Anti-Rabbit IgG H\&L (HRP) secondary antibody (1:2,500; cat. no. ab205718; Abcam) at $37^{\circ} \mathrm{C}$ for $45 \mathrm{~min}$. Membranes were scanned using an EasySee Western Blot kit (Beijing TransGen Biotech Co., Ltd.). Relative protein expression was semi-quantified using Image-Pro Plus software (version 6.0; Media Cybernetics, Inc.). $\beta$-actin (1:2,000; cat. no. ab8226; Abcam) was used as a loading control.

Statistical analysis. Data are presented as the mean \pm SD of three independent experiments. Comparisons were conducted using one-way ANOVA followed by Tukey's post hoc test when multiple groups were being compared, or using unpaired Student's t-test if two groups were being compared. Paired samples were analyzed using a paired Student's t-test. Correlation was assessed using Pearson's analysis. $\mathrm{P}<0.05$ was considered to indicate a statistically significant difference. All calculations were performed using SPSS 18.0 (SPSS, Inc.).

\section{Results}

NEAT1 and FGFR1 expression levels are elevated, whereas miR-377 expression is decreased in CC tissues and cell lines. Firstly, the expression levels of NEAT1, FGFR1 and miR-377 were detected in the tissues of 10 patients with $\mathrm{CC}$. The basic clinical characteristics of the patients with $\mathrm{CC}$ are listed in Table I. As shown in Fig. 1A-C, the expression levels of lncRNA NEAT1 and FGFR1 were significantly upregulated, whereas the expression levels of miR-377 were significantly downregulated in $\mathrm{CC}$ tissues. In addition, a Pearson's analysis was conducted to investigate correlations among NEAT1, FGFR1 and miR-377. The analysis showed that NEAT1 and miR-377, and FGFR1 and miR-377 expression were negatively correlated, whereas NETA1 and FGFR1 expression were positively correlated; however, these correlations were not significant, which may be due to small number of samples (Fig. 1D-F). Similar results were observed in CC cell lines. In all CC cell lines, the expression levels of NEAT1 and 
A
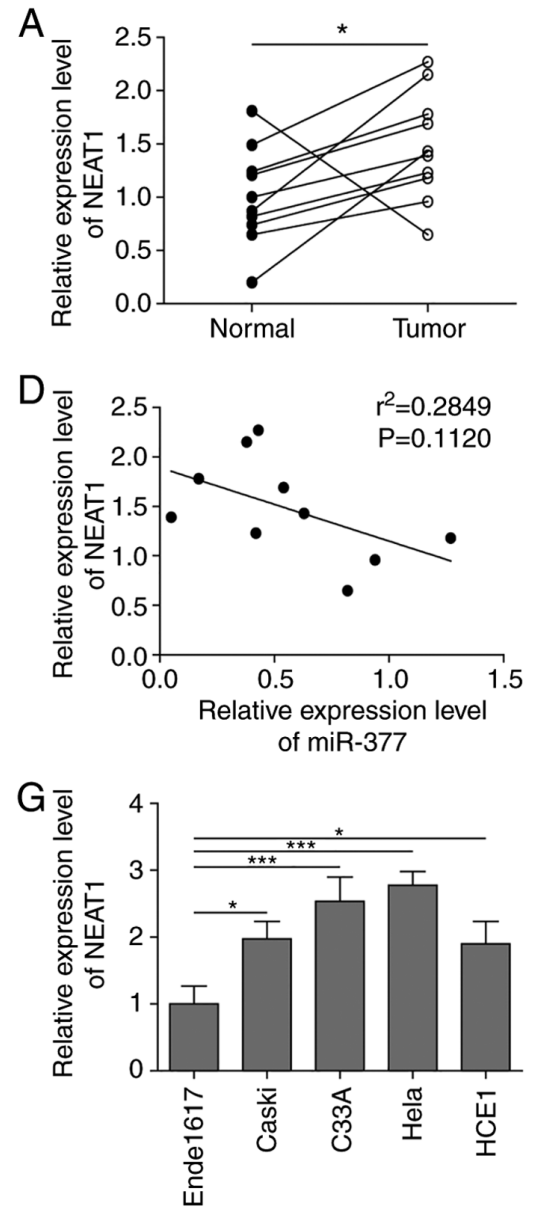

B

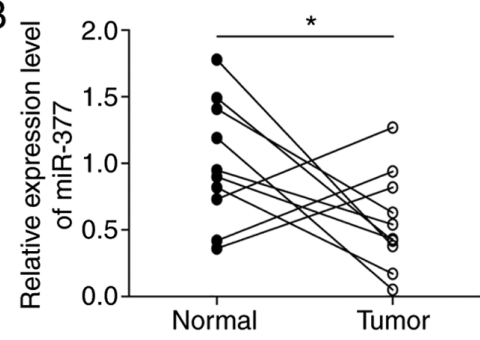

$\mathrm{E}$

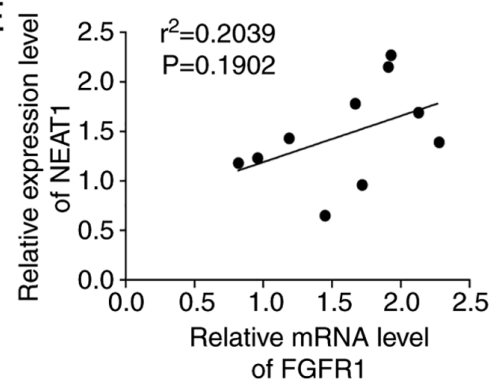

$H$

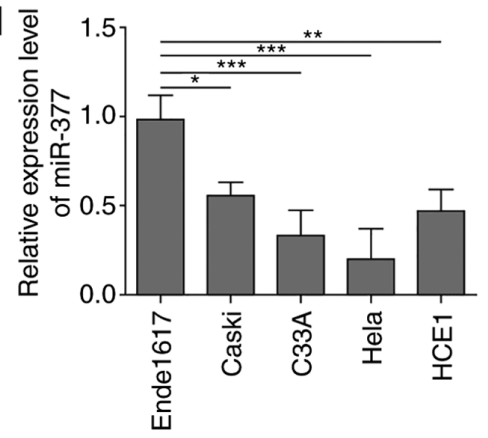

$\mathrm{C}$

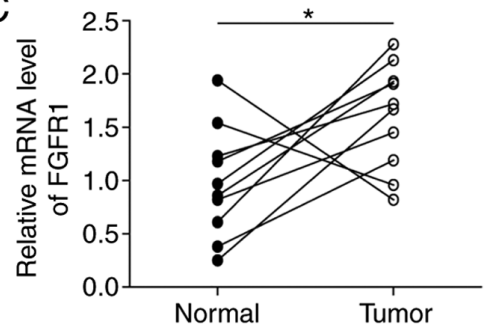

$\mathrm{F}$
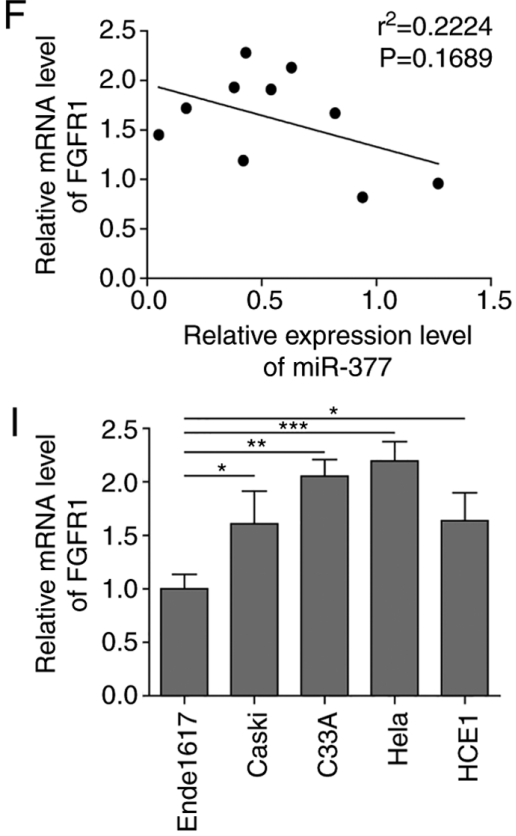

Figure 1. NEAT1 and FGFR1 expression levels are elevated, whereas miR-377 expression is decreased in CC tissues and cell lines. The expression levels of (A) NEAT1, (B) miR-377 and (C) FGFR1 were determined by RT-qPCR in CC tissues. n=10. Pearson's analysis was conducted to investigate correlations between (D) NEAT1 and miR-377, (E) NEAT1 and FGFR1, and (F) miR-377and FGFR1. The expression levels of (G) NEAT1, (H) miR-377 and (I) FGFR1 were determined by RT-qPCR in CC cell lines and ende1617 cells. $\mathrm{n}=5 .{ }^{*} \mathrm{P}<0.05,{ }^{* *} \mathrm{P}<0.01,{ }^{* * *} \mathrm{P}<0.001$. FGFR1, fibroblast growth factor receptor 1 ; miR, microRNA; CC, cervical cancer; RT-qPCR, reverse transcription-quantitative PCR.

FGFR1 were markedly elevated, whereas miR-377 expression was decreased compared with the expression levels in ende1617 cells (Fig. 1G-I), indicating that NEAT1, FGFR1 and miR-377 were abnormally expressed in CC.

Silencing NEAT1 suppresses cell viability and migration, and induces apoptosis of CC cells through regulation of miR-377. According to Fig. 1G, NEAT1 was most prominently expressed in HeLa and C33A cells; therefore, HeLa and C33A cells were selected and NEAT1 was silenced via transfection of cells with sh-NEAT1, in order to further investigate the role of NEAT1 in CC. After successfully transfecting the HeLa and C33A cell lines with sh-NEAT1 (Fig. 2A), it was revealed that the expression levels of miR-377 were significantly upregulated when NEAT1 was knocked down compared with in the sh-NC group (Fig. 2B). Conversely, after knockdown of NEAT1, the mRNA and protein expression levels of FGFR1 were significantly reduced (Fig. 2C). Compared with in the sh-NC group, when NEAT1 was suppressed, cell viability and migration were significantly inhibited (Fig. 2D and E), whereas the rate of apoptosis was significantly enhanced (Fig. 2F). A binding relationship was predicted between NEAT1 and miR-377 using bioinformatics analysis, and a NEAT1 3'-UTR mut was constructed (Fig. 2G).
Subsequently, the transfection efficiency of miR-377 mimics and inhibitor was detected. It was demonstrated that in both Hela and C33A cell lines, transfection with miR-377 mimics resulted in a significant overexpression of miR-377, whereas the miR-377 inhibitor led to marked downregulation of miR-377 (Fig. 2H). A dual luciferase reporter gene assay was then conducted. The results revealed that when transfected with miR-377 mimics, the luciferase activity in wt-NEAT1 cells was significantly reduced, whereas transfection with the miR-377 inhibitor resulted in significantly increased luciferase activity in wt-NEAT1 cells. However, no significant differences were detected in mut-NEAT1 cells (Fig. 2I). These results suggested that knockdown of NEAT1 increased miR-377 expression, suppressed cell viability and migration, and enhanced cell apoptosis.

Overexpression of miR-377 suppresses cell viability and migration, and induces apoptosis of CC cells by targeting FGFR1. The present study successfully induced overexpression of miR-377 in both HeLa and C33A cells (Fig. 2H). After transfection with miR-377 mimics, the mRNA and protein expression levels of FGFR1 were significantly downregulated in HeLa and C33A cells (Fig. 3A and B). In addition, overexpression of miR-377 resulted in marked 

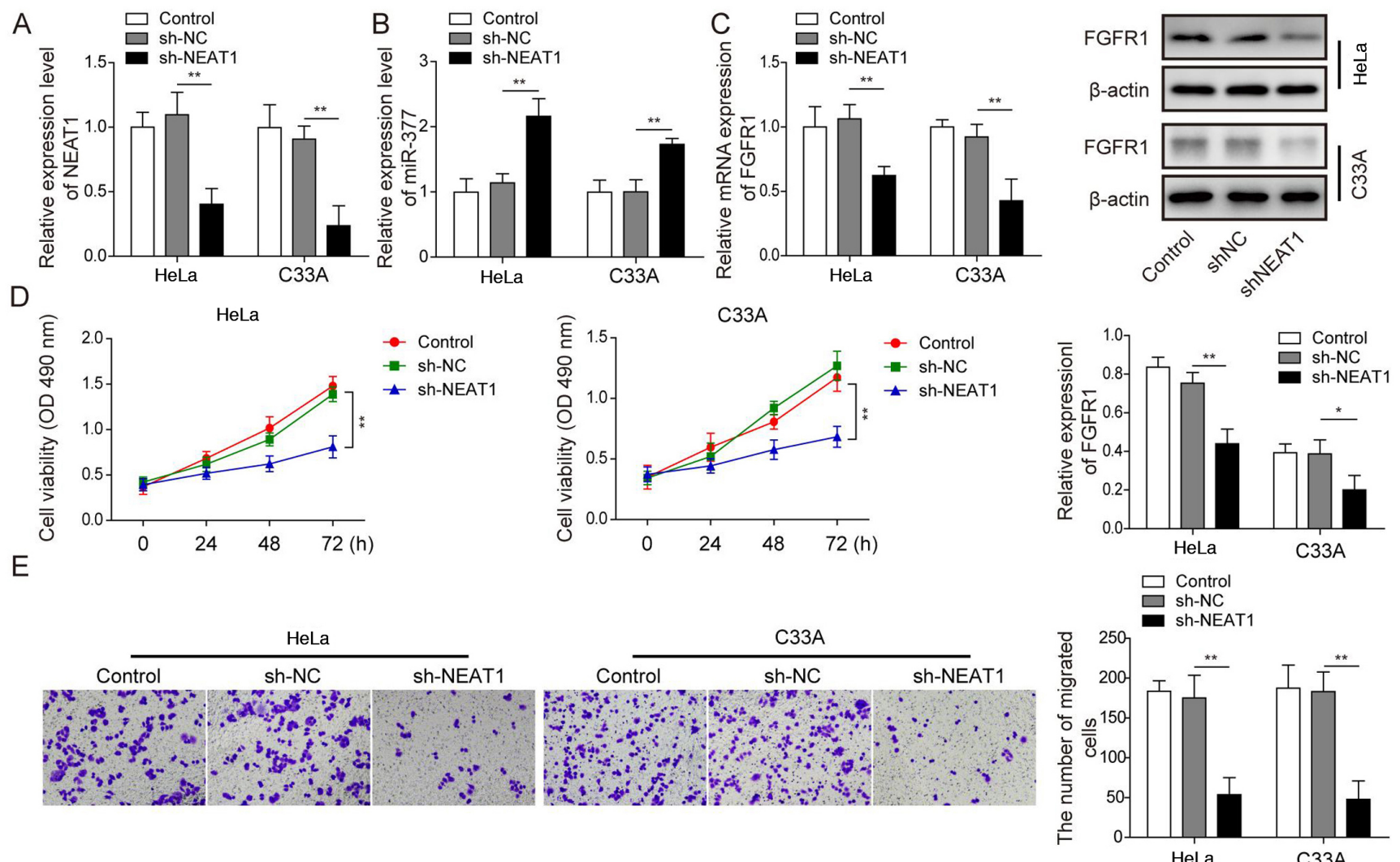

$\mathrm{F}$
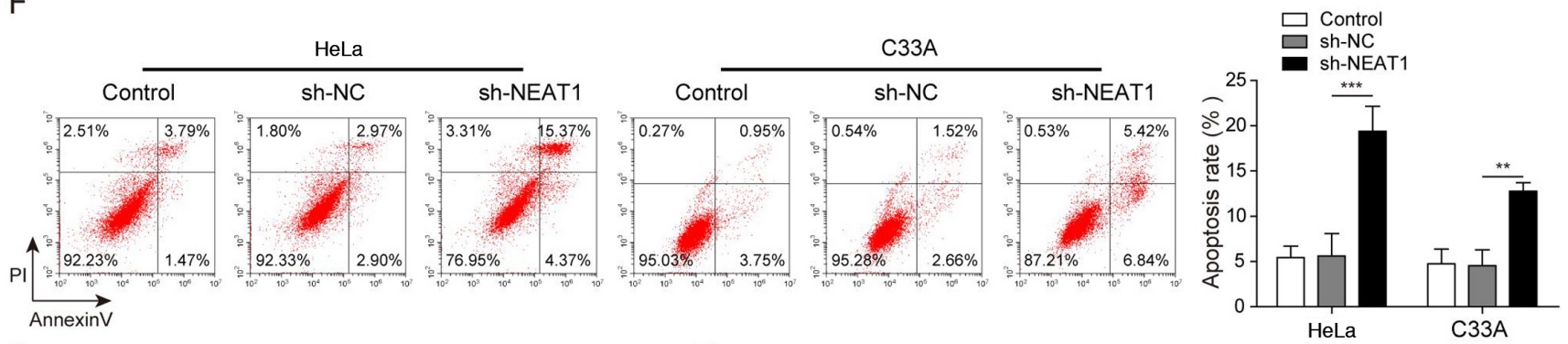

G
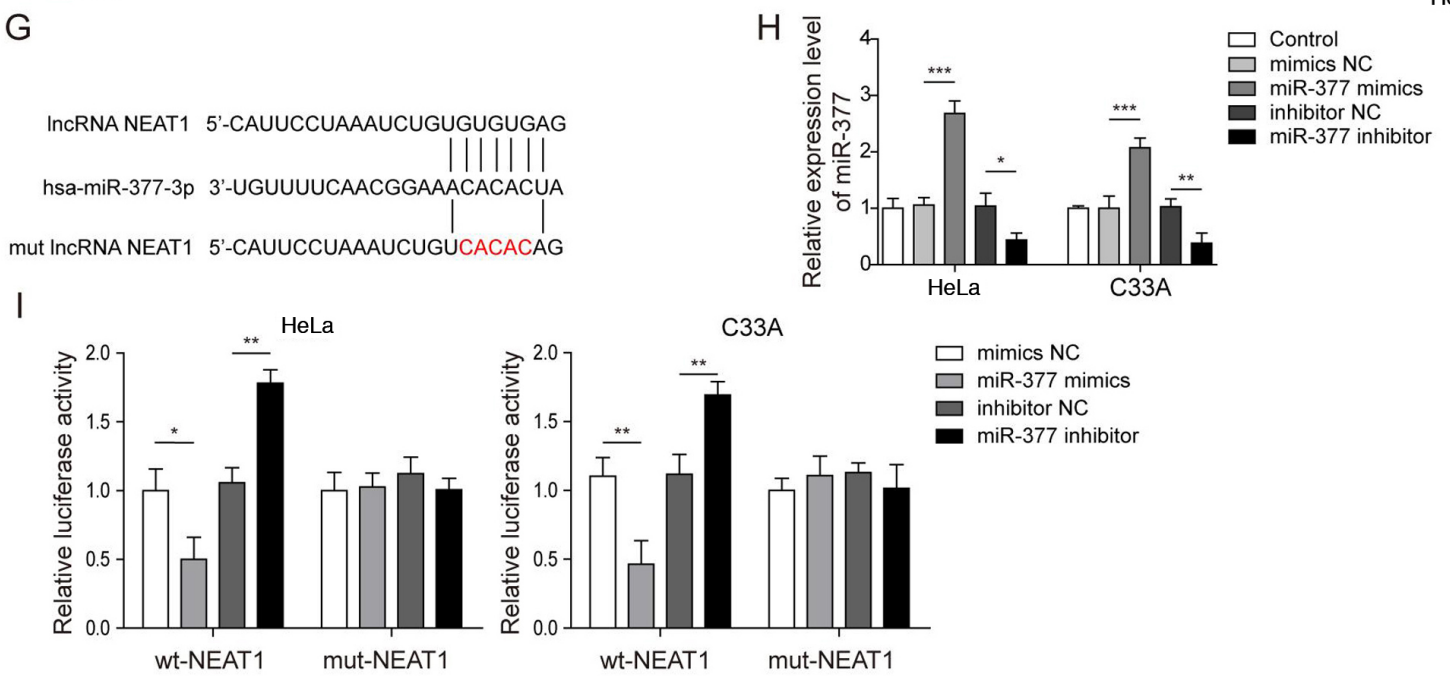

Figure 2. Silencing NEAT1 suppresses cell viability and migration, and induces apoptosis of cervical cancer cells through regulation of miR-377. The expression levels of (A) NEAT1 and (B) miR-377 were determined by RT-qPCR in HeLa and C33A cells transfected with sh-NEAT1 or sh-NC. (C) Detection of FGFR1 mRNA and protein expression levels in HeLa and C33A cells by RT-qPCR and western blotting after knockdown of NEAT1. (D) Cell viability was measured using MTT assays in HeLa and C33A cells transfected with sh-NEAT1 or sh-NC. (E) Cell migration was detected using Transwell assays in HeLa and C33A cells transfected with sh-NEAT1 or sh-NC. Magnification, x200. (F) Cell early and late apoptosis was measured via flow cytometry in HeLa and C33A cells transfected with sh-NEAT1 or sh-NC. (G) Binding site of miR-377 with wt NEAT1 3'-UTR and mut NEAT1 3'-UTR is shown. (H) Transfection efficiency of miR-377 mimics and inhibitor was determined in both HeLa and C33A cell lines using RT-qPCR. (I) Dual luciferase reporter assay results of cells were transfected with wt-NEAT1 or mut-NEAT1 3'-UTR and miR-377 inhibitor or mimics. Luciferase intensity was detected and analyzed. n=3. "P<0.05, ${ }^{* *} \mathrm{P}<0.01,{ }^{* * *} \mathrm{P}<0.001$. FGFR1, fibroblast growth factor receptor 1; miR, microRNA; RT-qPCR, reverse transcription-quantitative PCR; sh, short hairpin RNA; NC, negative control; wt, wild-type; mut, mutant; 3'-UTR, 3'-untranslated region; lncRNA, long non-coding RNA. 

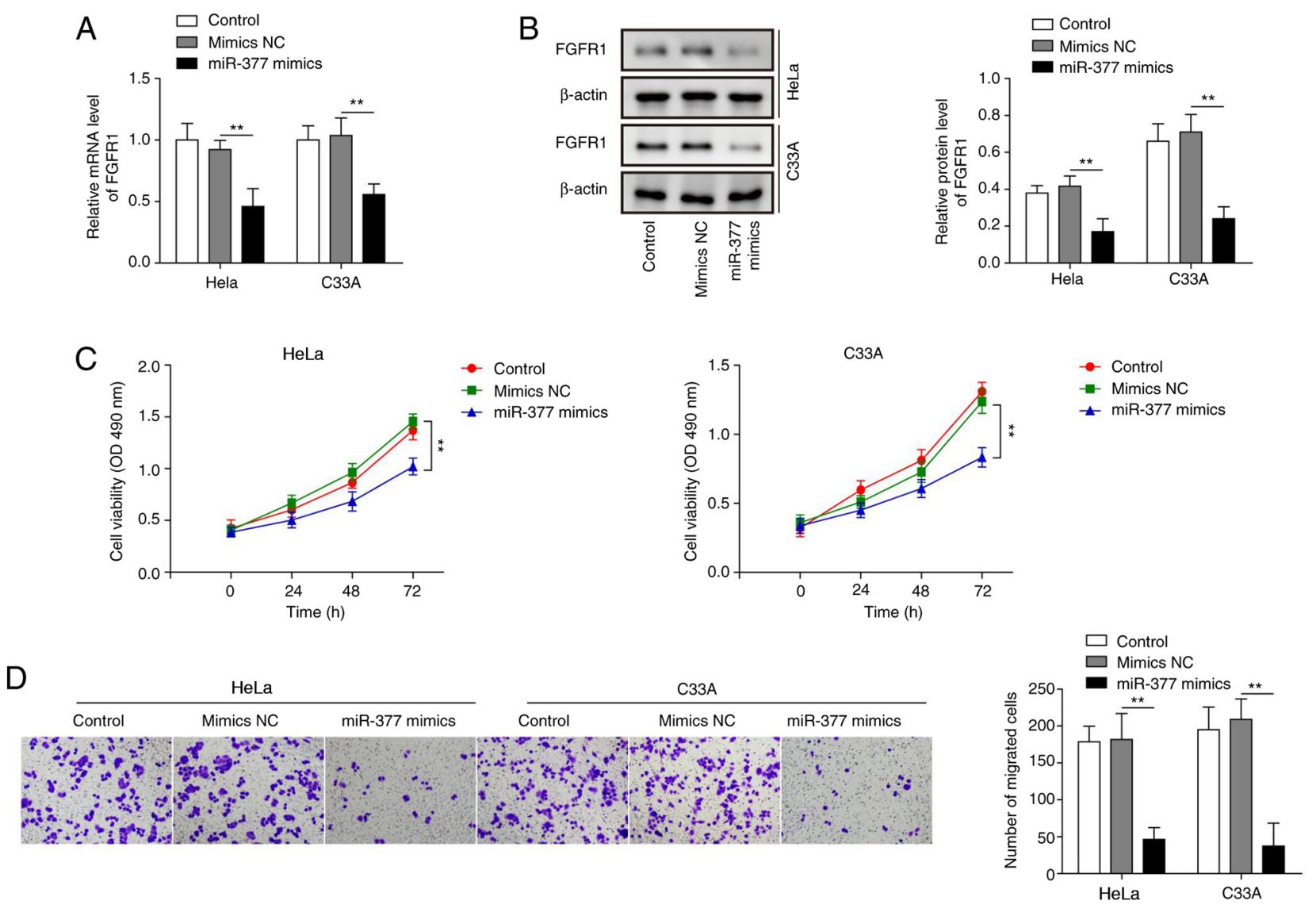

E
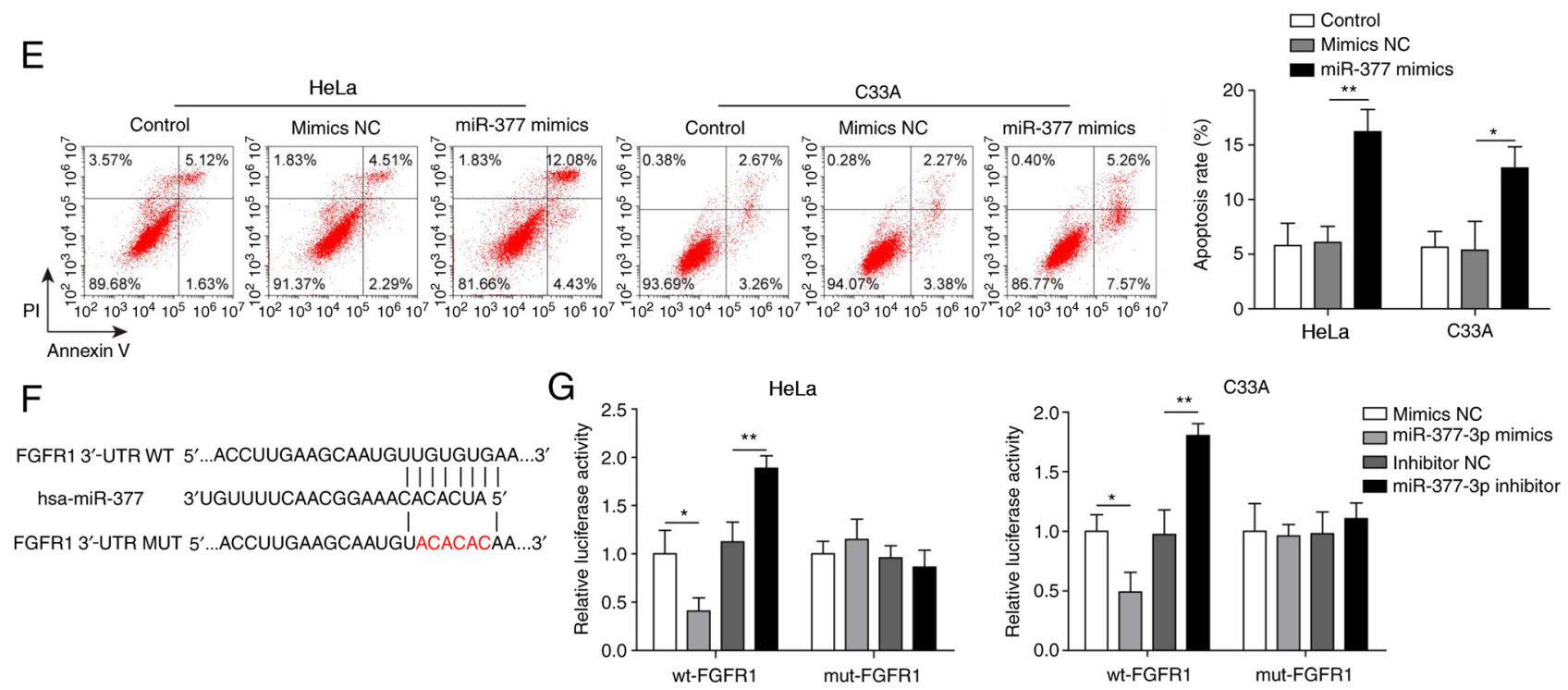

Figure 3. Overexpression of miR-377 suppresses cell viability and migration, and induces apoptosis of cervical cancer cells by targeting FGFR1. (A) mRNA and (B) protein expression levels of FGFR1 were determined by RT-qPCR and western blotting in HeLa and C33A cells transfected with miR-377 mimics or NC. (C) Cell viability was measured using MTT assays in HeLa and C33A cells transfected with miR-377 mimics or NC. (D) Transwell assays were used to detect the migration of cells overexpressing miR-377. (E) Flow cytometric analysis of apoptosis in HeLa and C33A cells transfected with miR-377 mimics or NC. Magnification, x200. (F) Binding site of miR-377 with wt FGFR1 3'-UTR and mut FGFR1 3'-UTR is shown. (G) Dual luciferase reporter assay results of cells were transfected with wt-FGFR1 or mut-FGFR1 3'-UTR and miR-377 inhibitor or mimics. Luciferase intensity was detected and analyzed. n=3. " $\mathrm{P}<0.05$, ${ }^{* *} \mathrm{P}<0.01$. FGFR1, fibroblast growth factor receptor 1; miR, microRNA; RT-qPCR, reverse transcription-quantitative PCR; NC, negative control; wt, wild-type; mut, mutant; 3'-UTR, 3'-untranslated region.

inhibition of cell viability and migration (Fig. 3C and D), and significant promotion of cell apoptosis (Fig. 3E). To confirm the binding relationship between miR-377 and FGFR1 predicted by bioinformatics analysis, the binding site was first predicted using TargetScan 7.2 and a mut FGFR1 3'-UTR was constructed (Fig. 3F). Subsequently, a dual luciferase reporter assay was conducted. The results revealed that the luciferase activity was markedly decreased in wt-FGFR1 cells transfected with miR-377 mimics and that transfection with the miR-377 inhibitor led to markedly increased luciferase 

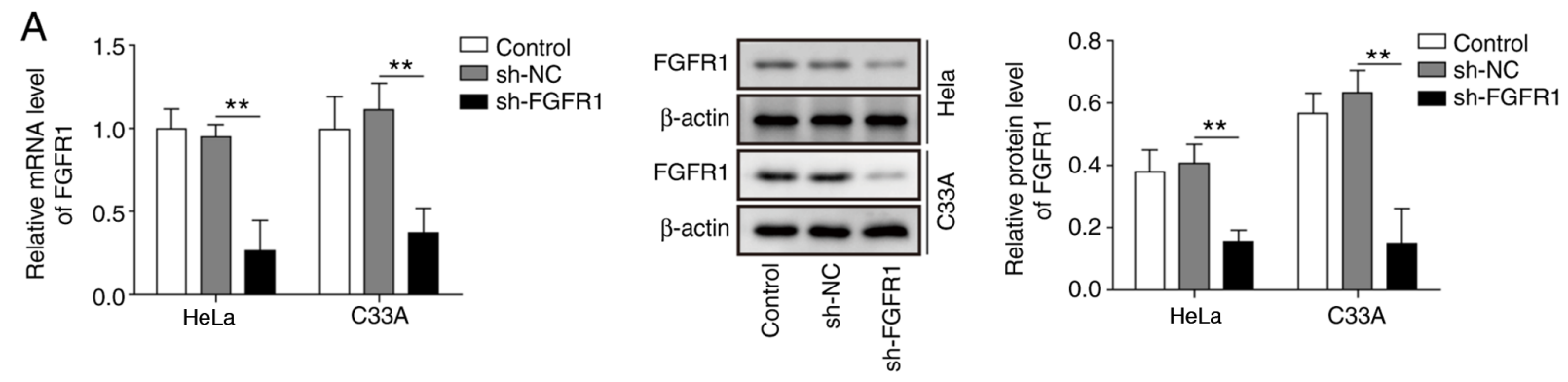

B
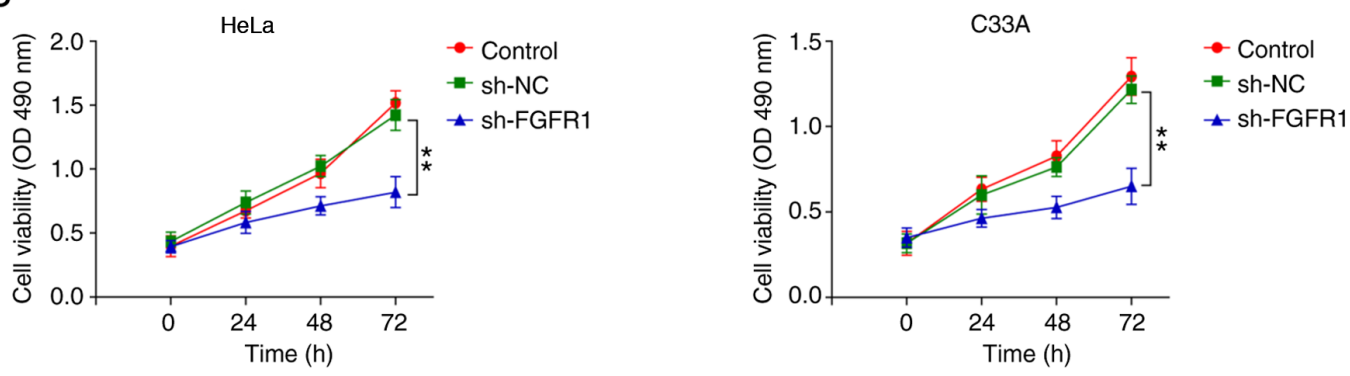

C
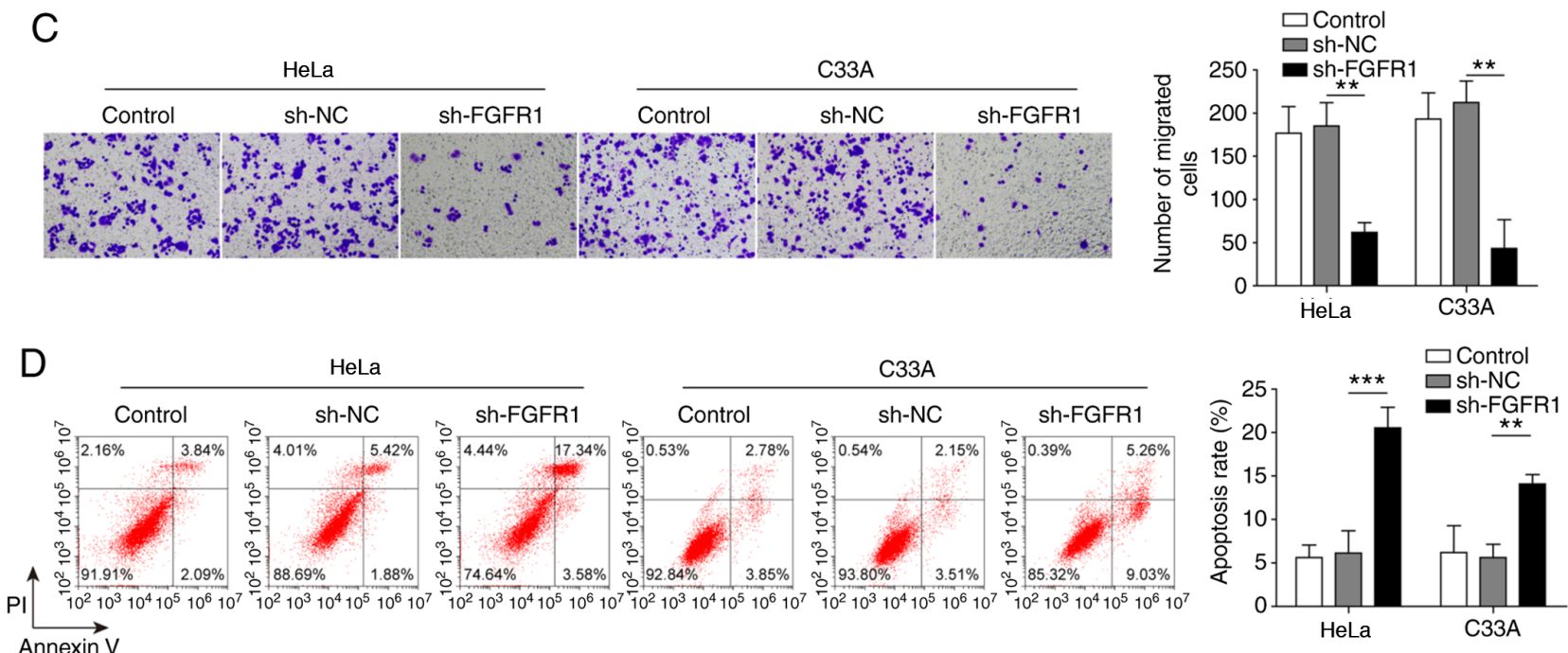

Figure 4. Inhibition of FGFR1 leads to decreased cell viability and migration, and increased apoptosis of cervical cancer cells. (A) mRNA and protein expression levels of FGFR1 were determined by reverse transcription-quantitative PCR and western blotting in HeLa and C33A cells transfected with sh-FGFR1 or sh-NC. (B) Cell viability was measured using MTT assays in HeLa and C33A cells transfected with sh-FGFR1 or sh-NC. (C) Transwell assays were used to detect cell migration in cells with FGFR1 knockdown. Magnification, x200. (D) Apoptosis was measured by flow cytometry in HeLa and C33A cells transfected with sh-FGFR1 or sh-NC. $n=3 .{ }^{* *} \mathrm{P}<0.01,{ }^{* * *} \mathrm{P}<0.001$. FGFR1, fibroblast growth factor receptor 1; sh, short hairpin RNA; NC, negative control.

activity in wt-FGFR1 cells (Fig. 3G). However, no significant difference was found in mut-FGFR1 cells. These results suggested that overexpression of miR-377 may inhibit CC cell viability and migration, and induce cell apoptosis through targeting FGFR1.

Inhibition of FGFR1 leads to decreased cell viability and migration, and increased apoptosis of CC cells. To further explore the effects of FGFR1 on CC cells, FGFR1 was suppressed in HeLa and C33A cells, and the cell functions were evaluated. As shown in Fig. 4A, the mRNA and protein expression levels of FGFR were significantly suppressed by transfection with sh-FGFR1. Knockdown of FGFR1 led to a marked decrease in cell viability and migration, and significantly increased cell apoptosis (Fig. 4B-D). These results suggested that inhibition of FGFR1 may restrict the oncogenic progression of CC cells.
NEATI affects CC cells through regulation of the miR-377/FGFR1 axis. HeLa and C33A cells were transfected with both sh-NEAT1 and miR-377 inhibitor to confirm the relationship between NEAT1 and the miR-377/FGFR1 axis, and its role in CC cell functions. FGFR1 expression was significantly decreased when NEAT1 was suppressed, whereas FGFR1 expression was significantly increased after transfection with the miR-377 inhibitor (Fig. 5A). Similarly, FGFR1 protein expression levels were decreased following knockdown of NEAT1, whereas FGFR1 protein expression levels were increased after miR-377 inhibition (Fig. 5B). Notably, transfection with the miR-377 inhibitor markedly reversed the effects of sh-NEAT1. Similarly, the inhibitory effects of sh-NEAT1 on cell viability and migration, and the promotive effects of sh-NEAT1 on cell apoptosis were markedly reversed by inhibition of miR-377 in CC cells (Fig. 5C-E). 


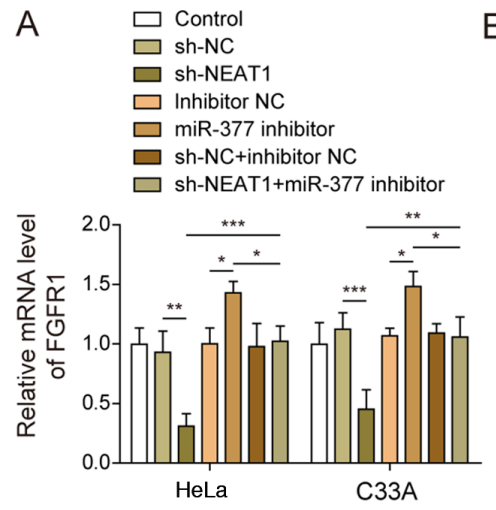

C

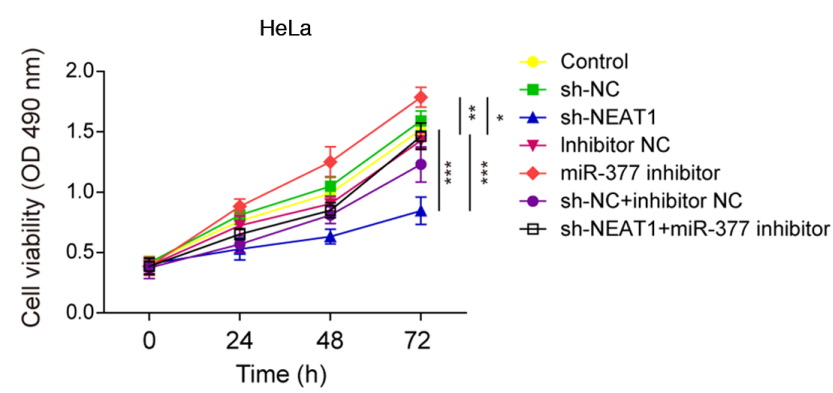

D

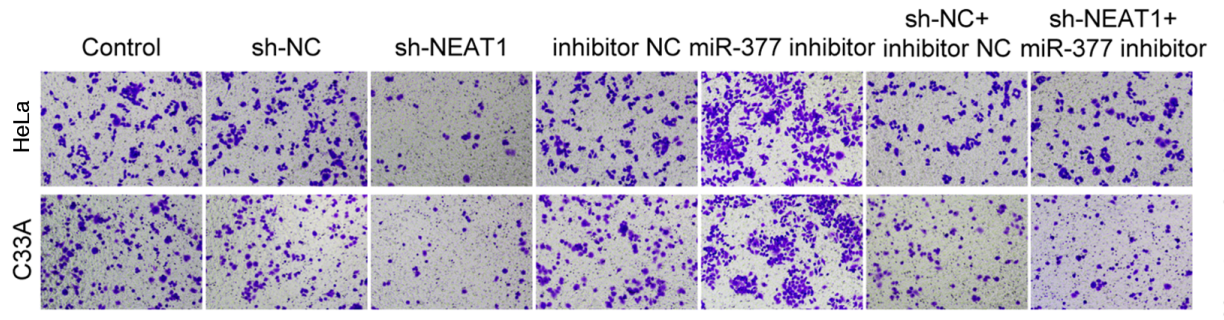

E

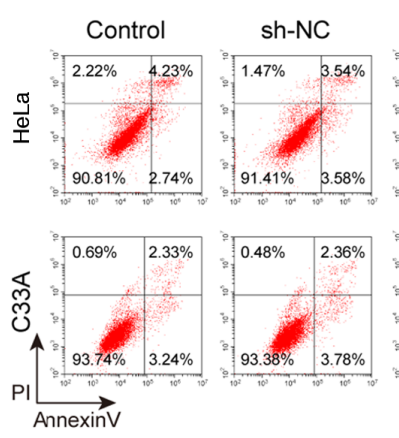

B

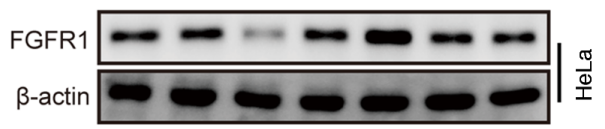

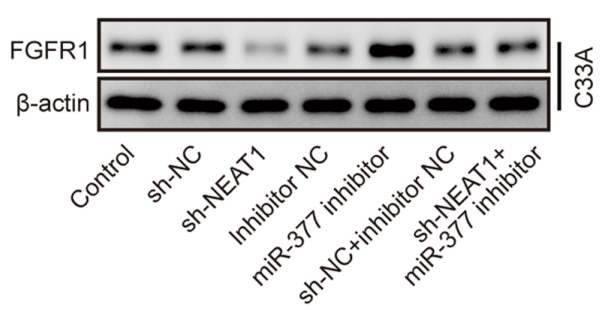

C33A $\square$ Control

$\square$ sh-NC

$\square$ sh-NEAT1

$\square$ Inhibitor NC

$\square$ miR-377 inhibitor

$\square$ sh-NC+inhibitor NC

$\square$ sh-NEAT1+miR-377 inhibitor

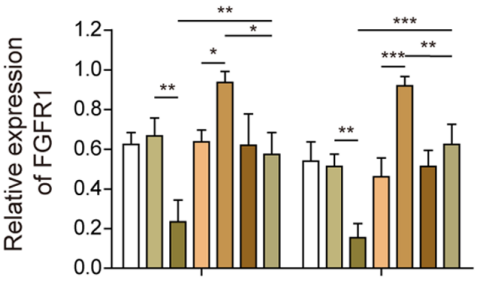

HeLa

C33A
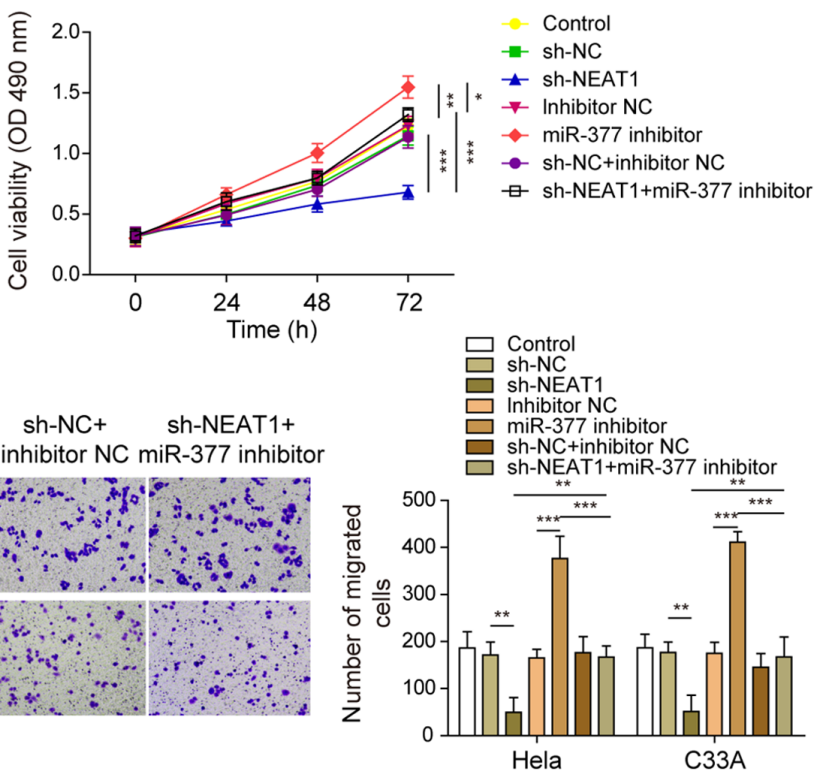

Hela

C $33 \mathrm{~A}$

Figure 5. NEAT1 affects cervical cancer cells through regulation of the miR-377/FGFR1 axis. (A) mRNA and (B) protein expression levels of FGFR1 were determined by reverse transcription-quantitative PCR and western blotting in HeLa and C33A cells transfected with sh-NEAT1, miR-377 inhibitor or both (C) Cell viability was measured using MTT assays in HeLa and C33A cells transfected with sh-NEAT1, miR-377 inhibitor or both. (D) Transwell assays were used to detect cell migration in cells transfected with sh-NEAT1, miR-377 inhibitor or both. Magnification, x200. (E) Apoptosis was measured via flow cytometry in HeLa and C33A cells transfected with sh-NEAT1, miR-377 inhibitor or both. $\mathrm{n}=3 .{ }^{*} \mathrm{P}<0.05,{ }^{* *} \mathrm{P}<0.01,{ }^{* * *} \mathrm{P}<0.001$. FGFR 1 , fibroblast growth factor receptor 1; miR, microRNA; sh, short hairpin RNA; NC, negative control.

Finally, the present study knocked down NEAT1 and overexpressed FGFR1 at the same time. In HeLa and C33A cell lines, transfection with sh-NEAT1 significantly decreased the expression levels of FGFR1, whereas co-transfection with the FGFR1 vector markedly reversed this effect (Fig. 6A). Furthermore, western blotting exhibited similar results (Fig. 6B). Similar to the results of miR-377 inhibition, overexpression of FGFR1 reversed the inhibitory effect of NEAT1 knockdown on cell viability and migration (Fig. 6C and D). In addition, overexpression of FGFR1 reversed the effect of sh-NEAT1 on cell apoptosis (Fig. 6E).

Taken together, these results demonstrated that inhibition of miR-377 may reverse the effects of NEAT1 knockdown, indicating that NEAT1 could influence CC cells through regulation of the miR-377/FGFR1 axis. 

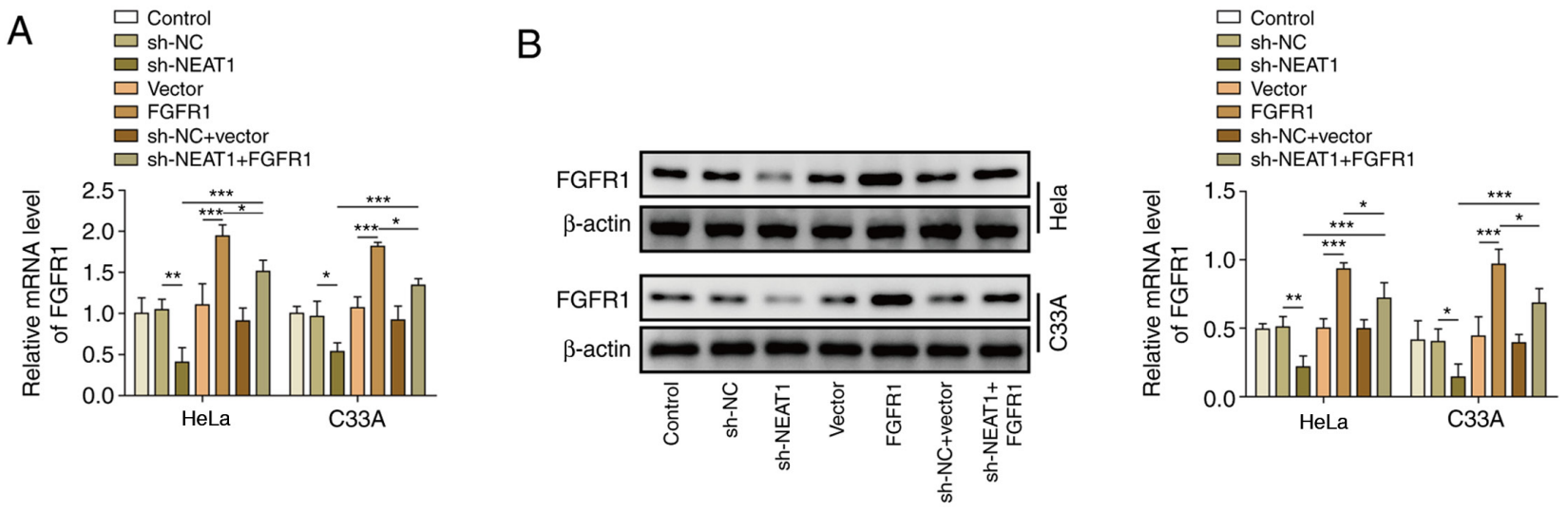

\section{C}
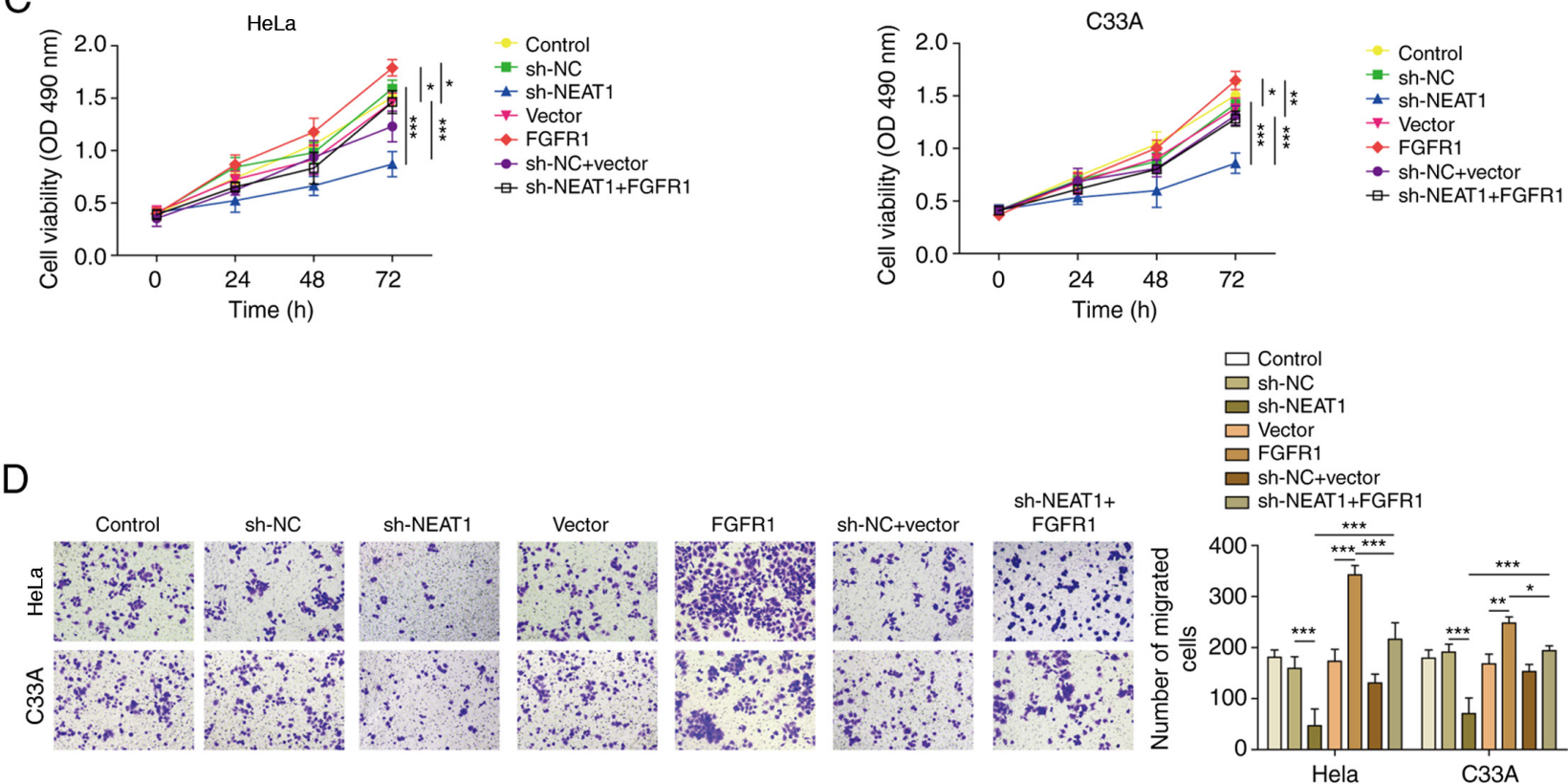

$\mathrm{E}$
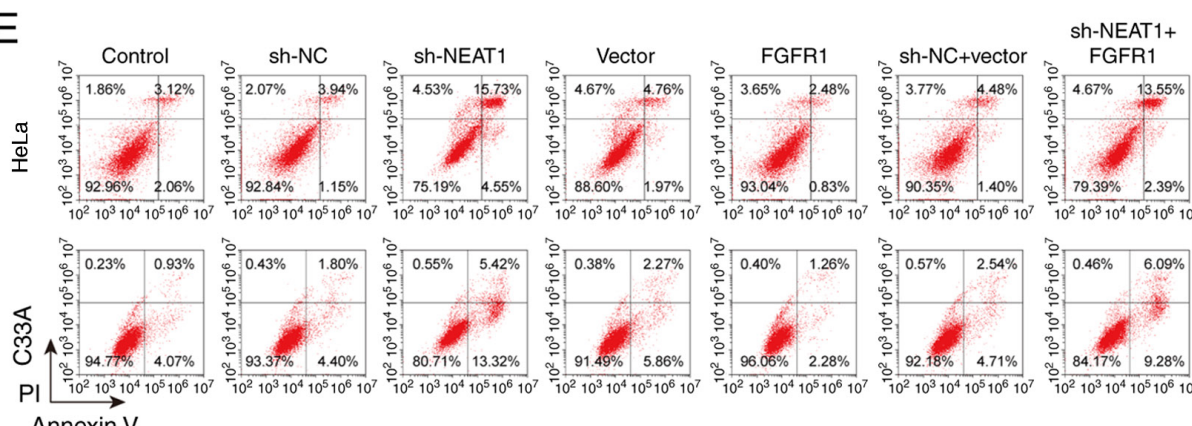

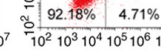
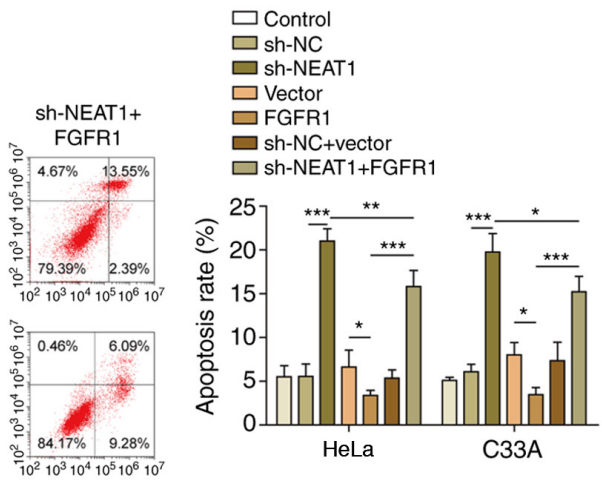

Figure 6. NEAT1 negatively regulates FGFR1. (A) mRNA and (B) protein expression levels of FGFR1 were determined by reverse transcription-quantitative PCR and western blotting in HeLa and C33A cells transfected with sh-NEAT1, FGFR1 or both. (C) Cell viability was measured using MTT assays in HeLa and C33A cells transfected with sh-NEAT1, FGFR1 or both. (D) Transwell assays were used to detect cell migration in HeLa and C33A cells transfected with sh-NEAT1, FGFR1 or both. Magnification, x200. (E) Apoptosis was measured via flow cytometry in HeLa and C33A cells transfected with sh-NEAT1, FGFR1 or both. $\mathrm{n}=3 .{ }^{*} \mathrm{P}<0.05,{ }^{* *} \mathrm{P}<0.01,{ }^{* * *} \mathrm{P}<0.001$. FGFR1, fibroblast growth factor receptor 1 ; sh, short hairpin RNA; NC, negative control.

\section{Discussion}

$\mathrm{CC}$ is one of the most common types of malignant gynecological cancer. Despite numerous efforts to uncover the mechanisms underlying cervical carcinogenesis, the molecular signaling involved in CC development remains unclear. In recent years, the role of lncRNAs and miRNAs in cancer, including in CC, has been noted in several studies (24-26). However, few studies have reported the roles of 1ncRNA NEAT1 and miR-377 in CC $(27,28)$. The present study demonstrated that inhibition of NEAT1 suppressed cell viability and migration, and promoted apoptosis of CC cells by regulating the miR-377/FGFR1 axis. 
NEAT1 has been reported as a tumor promotor in several types of cancer. Wang et al (29) demonstrated that NEAT1 could facilitate cancer development by regulating the miR-107/CDK6 pathway in laryngeal squamous cell cancer. In addition, NEAT1 has been reported to be influenced by Oct 4 and promoted the lung cancer process (30). NEAT1 was also shown to promote epithelial-mesenchymal transition (EMT) in breast cancer and induce paclitaxel resistance in ovarian cancer $(31,32)$. The present study revealed that NEAT1 was upregulated in CC tissues and cell lines, and that knockdown of NEAT1 inhibited cell viability and migration, and promoted cell apoptosis.

The role of miR-377 in cancer development has also been reported in several studies. Rastogi et al (33) demonstrated that a decrease in miR-377 promoted cell growth and migration in oral squamous cell carcinoma. In another study, Azizi et al (34) demonstrated that miR-377 could inhibit the expression of DNMT1 and demethylate tumor suppressor genes, leading to reversal of cancerous phenotypes. In a recent study, miR-377 was observed to inhibit cell proliferation and invasion of CC through targeting of zinc finger E-box-binding homeobox (28). However, to the best of our knowledge, the relationship between miR-377 and FGFR1, and between miR-377 and NEAT1 in CC has not yet been reported. The present study demonstrated that miR-377 was downregulated in CC and targeted FGFR1, that this process may be regulated by NEAT1.

The anticancer effects induced by FGFR1 inhibition have been reported in previous studies. Wang et al (35) reported that FGFR1 could promote cell viability and EMT in lung cancer by regulating the ERK1/2-SOX2 axis. Golfmann et al (36) revealed that dual inhibition of FGFR1 and VEGF receptor 1 led to multiple synergistic anti-angiogenic treatment effects in FGFR1-amplified breast cancer. Another study demonstrated that FGFR1 was associated with resistance to estrogen deprivation in estrogen receptor-positive breast cancer (37). In addition, in a recent study, Zhan et al (20) revealed that miR-377 could directly target FGFR1 and suppress the development of hepatocellular carcinoma. However, to date, to the best of our knowledge, no study has focused on FGFR1 in CC. The present study reported that FGFR1 was upregulated in $\mathrm{CC}$ and that inhibition of FGFR1 could result in suppression of CC.

The present study has some limitations. Firstly, the in vivo effects of NEAT1 on CC were not assessed. Secondly, whether overexpression of other miRNAs, such as miR-133a and/or miR-9-5p, which have been reported in previous studies $(13,14)$, may influence the 'sponging' effect of NEAT1 on miR-377/FGR1 is not known. Finally, interactions between circulating RNAs and miRNAs should be further investigated in $\mathrm{CC}$, because several studies have revealed potential relationships between circRNAs and miRNAs in CC development $(38,39)$. All these interactions require further analysis.

In conclusion, the present study investigated the role of the NEAT1/miR-377/FGFR1 axis in CC development, and revealed that inhibition of NEAT1 suppressed cell viability and migration, and promoted apoptosis of CC cells through targeting miR-377 to regulate FGFR1. These results may provide deeper insights into the role of the NEAT1/miR-377/FGFR1 axis in CC development.

\section{Acknowledgements}

Not applicable.

\section{Funding}

The present study was supported by a grant from Shandong Province Medical and Health Technology Development Project (grant no. 2017ws191).

\section{Availability of data and materials}

All data generated or analyzed during this study are included in this published article.

\section{Authors' contributions}

FG guaranteed the integrity of the study, and conceived and designed the study. TL revised the article for important intellectual content. WCJ and TL performed experimental studies and acquired data. NL and WW drafted manuscript analysis, analyzed the data and performed statistical analysis. FG and WW confirm the authenticity of all the raw data. All authors agreed to be accountable for all aspects of the work in ensuring that questions related to the accuracy or integrity of any part of the work are appropriately investigated and resolved. All authors read and approved the final manuscript.

\section{Ethics approval and consent to participate}

Written informed consent was obtained from all patients for the biological studies, and the present study was approved by the Ethics Committee of Shandong Provincial Hospital.

\section{Patient consent for publication}

Not applicable.

\section{Competing interests}

The authors declare that they have no competing interests.

\section{References}

1. Shrestha AD, Neupane D, Vedsted P and Kallestrup P: Cervical cancer prevalence, incidence and mortality in low and middle income countries: A systematic review. Asian Pacific journal of cancer prevention. Asian Pac J Cancer Prev 19: 319-324, 2018.

2. Dykens JA, Linn AM, Irwin T, Peters KE, Pyra M, Traoré F, Touré Diarra M, Hasnain M, Wallner K, Linn P, et al: Implementing visual cervical cancer screening in Senegal: A cross-sectional study of risk factors and prevalence highlighting service utilization barriers. Int J Womens Health 9: 59-67, 2017.

3. Escobar N and Plugge E: Prevalence of human papillomavirus infection, cervical intraepithelial neoplasia and cervical cancer in imprisoned women worldwide: A systematic review and meta-analysis. J Epidemiol Community Health 74: 95-102, 2020.

4. Cohen PA, Jhingran A, Oaknin A and Denny L: Cervical cancer. Lancet 393: 169-182, 2019.

5. Peng L, Yuan X, Jiang B, Tang Z and Li GC: LncRNAs: Key players and novel insights into cervical cancer. Tumour Biol 37: 2779-2788, 2016

6. Bahrami A, Hasanzadeh M, ShahidSales S, Yousefi Z, Kadkhodayan S, Farazestanian M, Joudi Mashhad M, Gharib M, Mahdi Hassanian S and Avan A: Clinical significance and prognosis value of Wnt signaling pathway in cervical cancer. J Cell Biochem 118: 3028-3033, 2017.

7. Aalijahan $\mathrm{H}$ and Ghorbian S: Long non-coding RNAs and cervical cancer. Exp Mol Pathol 106: 7-16, 2019. 
8. Yuan LY, Qin X, Li L, Zhou J, Zhou M, Li X, Xu Y, Wang XJ and Xing $\mathrm{H}$ : The transcriptome profiles and methylation status revealed the potential cancer-related lncRNAs in patients with cervical cancer. J Cell Physiol 234: 9756-9763, 2019.

9. Huang J, Liu T, Shang C, Zhao Y, Wang W, Liang Y, Guo L and Yao S: Identification of lncRNAs by microarray analysis reveals the potential role of IncRNAs in cervical cancer pathogenesis. Oncol Lett 15: 5584-5592, 2018.

10. Yu X, Li Z, Zheng H, Chan MT and Wu WKK: NEAT 1: A nove cancer-related long non-coding RNA. Cell Prolif 50: e12329, 2017.

11. Sun C, Li S, Zhang F, Xi Y, Wang L, Bi Y and Li D: Long non-coding RNA NEAT1 promotes non-small cell lung cancer progression through regulation of miR-377-3p-E2F3 pathway. Oncotarget 7: 51784-51814, 2016.

12. Li W, Zhang Z, Liu X, Cheng X, Zhang Y, Han X, Zhang Y, Liu S, Yang J, Xu B, et al: The FOXN3-NEAT1-SIN3A repressor complex promotes progression of hormonally responsive breast cancer. J Clin Invest 127: 3421-3440, 2017.

13. Yuan LY, Zhou M, Lv H, Qin X, Zhou J, Mao X, Li X, Xu Y, Liu Y and Xing H: Involvement of NEAT1/miR-133a axis in promoting cervical cancer progression via targeting SOX4. J Cell Physiol 234: 18985-18993, 2019.

14. Xie Q, Lin S, Zheng M, Cai Q and Tu Y: Long noncoding RNA NEAT1 promotes the growth of cervical cancer cells via sponging miR-9-5p. Biochem Cell Biol 97: 100-108, 2019.

15. Trang P, Weidhaas JB and Slack FJ: MicroRNAs and cancer. In: The Molecular Basis of Human Cancer. Springer, New York, NY, pp277-286, 2017.

16. Park S, Eom K, Kim J, Bang H, Wang HY, Ahn S, Kim G, Jang H, Kim S, Lee D, et al: MiR-9, miR-21, and miR-155 as potential biomarkers for HPV positive and negative cervical cancer. BMC Cancer 17: 658, 2017.

17. Babion I, Jaspers A, van Splunter AP, van der Hoorn IA, Wilting SM and Steenbergen RD: miR-9-5p exerts a dual role in cervical cancer and targets transcription factor TWIST1. Cells 9: 65, 2019.

18. Wu H, Liu HY, Liu WJ, Shi YL and Dawei Bao D: miR-377-5p inhibits lung cancer cell proliferation, invasion, and cell cycle progression by targeting AKT1 signaling. J Cell Biochem: Nov 28 , 2018 (Epub ahead of print). doi: 10.1002/jcb.28091.

19. Li B, Xu WW, Han L, Chan KT, Tsao SW, Lee NP, Law S, Xu LY, Li EM, Chan KW, et al: MicroRNA-377 suppresses initiation and progression of esophageal cancer by inhibiting CD133 and VEGF. Oncogene 36: 3986-4000, 2017.

20. Zhan W, Liao X, Chen Z, Li L, Tian T, Yu L, Wang W and Hu Q: Circular RNA hsa circRNA 103809 promoted hepatocellular carcinoma development by regulating miR-377-3p/FGFR1/ERK axis. J Cell Physiol 235: 1733-1745, 2020.

21. Yuan H, Li ZM, Shao J, Ji WX, Xia W and Lu S: FGF2/FGFR1 regulates autophagy in FGFR1-amplified non-small cell lung cancer cells. J Exp Clin Cancer Res 36: 72, 2017.

22. Wu SF, Zhu HC, Gu FH, Huang BY and Liu HY: Characteristics of an established cervical carcinoma cell line HCE1. Hunan I Ko Ta Hsueh Hsueh Pao 25: 532-534, 2000 (In Chinese).

23. Livak KJ and Schmittgen TD: Analysis of relative gene expression data using real-time quantitative PCR and the 2(- $\Delta \Delta \mathrm{C}(\mathrm{T}))$ method. Methods 25: 402-408, 2001.

24. Tornesello ML, Faraonio R,Buonaguro L, Annunziata C, Starita N, Cerasuolo A, Pezzuto F, Tornesello AL and Buonaguro FM: The role of microRNAs, long non-coding RNAs, and circular RNAs in cervical cancer. Front Oncol 10: 150, 2020.
25. Peng WX, Koirala P and Mo YY: LncRNA-mediated regulation of cell signaling in cancer. Oncogene 36: 5661-5667, 2017.

26. Rupaimoole R and Slack FJ: MicroRNA therapeutics: towards a new era for the management of cancer and other diseases. Nat Rev Drug Discov 16: 203-222, 2017.

27. Han D, Wang J and Cheng G: LncRNA NEAT1 enhances the radio-resistance of cervical cancer via miR-193b-3p/CCND1 axis. Oncotarget 9: 2395-2409, 2018

28. $\mathrm{Ye} \mathrm{C}, \mathrm{Hu} \mathrm{Y}$ and Wang J: MicroRNA-377 targets zinc finger E-box-binding homeobox 2 to inhibit cell proliferation and invasion of cervical cancer. Oncol Res 27: 183-192, 2019.

29. Wang P, Wu T, Zhou H, Jin Q, He G, Yu H, Xuan L, Wang X, Tian L, Sun Y, et al: Long noncoding RNA NEAT1 promotes laryngeal squamous cell cancer through regulating miR-107/ CDK6 pathway. J Exp Clin Cancer Res 35: 22, 2016.

30. Jen J, Tang YA, Lu YH, Lin CC, Lai WW and Wang YC: Oct4 transcriptionally regulates the expression of long non-coding RNAs NEAT1 and MALAT1 to promote lung cancer progression. Mol Cancer 16: 104, 2017.

31. Zhang M, Wu WB, Wang ZW and Wang XH: lncRNA NEAT1 is closely related with progression of breast cancer via promoting proliferation and EMT. Eur Rev Med Pharmacol Sci 21: 1020-1026, 2017.

32. An J, Lv W and Zhang Y: LncRNA NEAT1 contributes to paclitaxel resistance of ovarian cancer cells by regulating ZEB1 expression via miR-194. OncoTargets Ther 10: 5377-5390, 2017.

33. Rastogi B, Kumar A, Raut SK, Panda NK, Rattan V, Joshi N and Khullar M: Downregulation of miR-377 promotes oral squamous cell carcinoma growth and migration by targeting HDAC9. Cancer Invest 35: 152-162, 2017.

34. Azizi M, Fard-Esfahani P, Mahmoodzadeh H, Fazeli MS, Azadmanesh K, Zeinali S and Teimoori-Toolabi L: MiR-377 reverses cancerous phenotypes of pancreatic cells via suppressing DNMT1 and demethylating tumor suppressor genes. Epigenomics 9: 1059-1075, 2017.

35. Wang K, Ji W, Yu Y, Li Z, Niu X, Xia W and Lu S: FGFR1-ERK1/2SOX2 axis promotes cell proliferation, epithelial-mesenchymal transition, and metastasis in FGFR1-amplified lung cancer. Oncogene 37: 5340-5354, 2018.

36. Golfmann K, Meder L, Koker M, Volz C, Borchmann S, Tharun L, Dietlein F, Malchers F, Florin A, Büttner R, et al: Synergistic anti-angiogenic treatment effects by dual FGFR1 and VEGFR1 inhibition in FGFR1-amplified breast cancer. Oncogene 37: 5682-5693, 2018.

37. Formisano L, Stauffer KM, Young CD, Bhola NE, Guerrero-Zotano AL, Jansen VM, Estrada MM, Hutchinson KE, Giltnane JM, Schwarz LJ, et al: Association of FGFR1 with ERa maintains ligand-independent ER transcription and mediates resistance to estrogen deprivation in $\mathrm{ER}^{+}$breast cancer. Clin Cancer Res 23: 6138-6150, 2017.

38. Gong J, Jiang H, Shu C, Hu MQ, Huang Y, Liu Q, Li RF and Wei YZ: Integrated analysis of circular RNA-associated ceRNA network in cervical cancer: Observational Study. Medicine (Baltimore) 98: e16922, 2019.

39. Meng Q, Li Y, Kong C, Gao X and Jiang X: Circ_0000388 exerts oncogenic function in cervical cancer cells by regulating miR-337-3p/TCF12 axis. Cancer Biother Radiopharm 36: 58-69, 2021.

This work is licensed under a Creative Common Attribution 4.0 International (CC BY-NC 4.0) License 